\title{
HSP70 regulates cell proliferation and apoptosis in actinomycin-D-treated lung cancer cells
}

\author{
Kai Zhang, Ruonan Zhai, Teng Xue, Xiaoyan Xu, Yanan Ren, Mingze Ma, Fengxian Shi, Hang Wang, \\ Na Wang, Fang Zhou \\ Department of Public Health, Zhengzhou University, Zhengzhou 450052, China \\ Contributions: (I) Conception and design: K Zhang, F Zhou; (II) Administrative support: W Yao, N Wang; (III) Provision of study materials \\ or patients: T Xue, X Xu; (IV) Collection and assembly of data: Y Ren, M Ma, F Shi; (V) Data analysis and interpretation: H Wang, R Zhai; \\ (VI) Manuscript writing: All authors; (VII) Final approval of manuscript: All authors. \\ Correspondence to: Fang Zhou; Na Wang. Department of Public Health, Zhengzhou University, Zhengzhou 450052, China. \\ Email: zhoufang@zzu.edu.cn; wfengqiao@zzu.edu.cn.
}

Background: Heat-shock protein 70 (HSP70) is a member of the heat-shock protein family which is expressed in various types of cancer and associated with apoptosis in cancer cells. However, the role of HSP70 in the regulation of c-Jun N-terminal kinase (JNK) and p38 mitogen-activated protein kinase (p38MAPK)-dependent growth and apoptosis in lung cancer cells remains largely unknown.

Methods: In this study, we conducted in vitro experiments. First, we examined the effect of HSP70 by treatment with mild heat and JNK/p38 MAPK inhibitors on cell proliferation in A549 cells by MTT assay. And then, through the use of flow cytometric assay, we examined the effect of HSP70 by treatment with mild heat and JNK/p38 MAPK inhibitors on cell apoptosis in A549 cells. Finally, we determined the role of HSP70 in the regulation of JNK and p38 MAPK-dependent growth and apoptosis in A549 cells by siRNA HSPAIA-2009 and Western blot.

Results: We found that treatment of the cells with mild heat and JNK/p38 MAPK pathway inhibitors (SP600125 and SB203580) promoted cell proliferation in the presence of actinomycin D (ActD) in A549 cells. We also showed that treatment with mild heat or SP600125 and SB203580 significantly slowed the steps of apoptosis induced by ActD in A549 cells. Moreover, we found that HSP70 overexpression induced by mild heat markedly decreased the expression of cell growth and apoptosis-related protein p-JNK, p38 and caspase-3. By contrast, knockdown of HSP70 by siRNA HSPAIA-2009 effectively promoted the expression of the JNK and p38 MAPK.

Conclusions: Our results indicate that HSP70 plays an important role in lung cancer growth and apoptosis through the activation of JNK and p38 MAPK signaling in actinomycin-D-treated lung cancer A549 cells.

Keywords: Lung cancer; A549 cell; actinomycin D (ActD); heat-shock protein 70 (HSP70); apoptosis; JNK

Submitted Oct 10, 2019. Accepted for publication Dec 20, 2019.

doi: $10.21037 /$ tcr.2019.12.100

View this article at: http://dx.doi.org/10.21037/tcr.2019.12.100

\section{Introduction}

The incidence and mortality of lung cancer is the highest of all malignant tumors worldwide (1). According to the World Cancer Report released by IARC in 2014, there were 14 million people suffering from cancer in 2012, and the number of those suffering from lung cancer was
1.8 million worldwide $(1,2)$ In addition, the morbidity of lung cancer takes first place among all types of malignant tumor $(1,3)$. Lung cancer is a threat to human health and a huge economic burden to society and families. Moreover, this situation seems to have worsened in many developing countries over the past few years. Thus, it is necessary to discover new therapeutic targets for lung cancer treatment 
and to identify the roles and underlying mechanisms of these targets in lung cancer.

Heat shock protein 70 (HSP70), a class of highly conserved proteins caused by stress, has been shown to be involved in the regulation of protein folding and refolding, protecting cells from stress damage; Heat shock factors can form a complex with transcriptional activity by phosphorylation or polymerization. This complex has the ability to identify targeting sequences related to heat shock elements and then launch stress-related gene transcription (4). The major stress-inducible HSP70, also termed HSPA1A, is frequently overexpressed in a large variety of different tumour types (5). overexpressed HSP70 are known to protect cancer cells from apoptotic cell death, promote tumour cell proliferation and migration, mediate therapy resistance and thus contribute to an aggressive tumour phenotype. For example, RNAimediated knockdown of HSP70 has been reported to reverse Cisplatin resistance in osteosarcoma cells (6), cervical cancer cells (7), ovarian cancer cells (8), and lung cancer cells (9). Recently, Many studies have proved that HSP70 was associated with apoptosis mediated by members of mitogen-activated protein kinases (JNK) c-Jun amino N-terminal kinase (MAPKs) and p38 MAPK, which play significant roles in cell growth, differentiation and apoptosis $(10,11)$. However, the functions of HSP70 in the regulation of activation of JNK and p38 MAPK in actinomycin D (ActD)-induced apoptosis in lung cancer remain unclear.

In this study, we treated lung cancer A549 cells with ActD to establish an apoptosis model, and then inhibited the JNK and p38 MAPK pathway with specific inhibitors. The effect of HSP70 and the p38 MAPK and JNK pathway on the survival of A549 cells was observed and analyzed. Additionally, we inhibited HSP70 using siRNA and analyzed the effect of HSP70 on cell viability and apoptosis in A549 cells. The level of expression of HSP70, the phosphorylation of JNK, and the activation of caspase- 3 were also detected. This study demonstrated the role of HSP70 in the process of proliferation and apoptosis in lung cancer cells, which provided theoretical support for new targets for lung cancer therapy.

\section{Methods}

\section{Cell lines and cell culture}

Human adenocarcinoma lung cell line A549 was purchased from Shanghai Institute of Biochemistry and Cell Biology. The cells were grown in RPMI 1640 medium supplemented with $10 \%$ fetal bovine serum without antibiotics at $37{ }^{\circ} \mathrm{C}$ in a humidified atmosphere of $5 \% \mathrm{CO}_{2}$. A549 cells at logarithmic growth phase were collected and dispensed within culture plates. After maintenance for $24 \mathrm{~h}$ at $37^{\circ} \mathrm{C}$, the cells were treated with mild heat treatment $\left(42^{\circ} \mathrm{C}, 30 \mathrm{~min}\right)$, or in the presence or absence of SP600125/SB203580 (Solarbio, Beijing). ActD (25 $\mathrm{g} / \mathrm{mL})$ in dimethylsulfoxide (DMSO) (Beyotime Institute of Biotechnology, Shanghai) was added $12 \mathrm{~h}$ later, except in the control group.

\section{Cell viability assay}

A549 cells at logarithmic growth phase were collected and the density of cells was adjusted to $1 \times 10^{4}$ cells $/ \mathrm{mL}$. Cells were added in 96-well culture plates ( $200 \mu \mathrm{L}$ per well) and incubated continuously at $37^{\circ} \mathrm{C}$ in a humidified atmosphere containing $5 \% \mathrm{CO}_{2}$ for $24 \mathrm{~h}$. MTT $(5 \mathrm{mg} / \mathrm{mL}, 20 \mu \mathrm{L}$ per well) was added at $24 \mathrm{~h}$ and again $48 \mathrm{~h}$ later; $4 \mathrm{~h}$ later, $100 \mu \mathrm{L}$ DMSO was added with vigorous shaking at $37^{\circ} \mathrm{C}$ until the purple crystal completely dissolved. The absorbance was measured at $570 \mathrm{~nm}$ by a micro plate reader. Cell viability was expressed as the optical density ratio of the treatment to control. Values were recorded as means $\pm \mathrm{SD}$ of three independent experiments.

\section{Apoptosis analysis}

A549 cells $\left(\geq 1 \times 10^{5} / \mathrm{mL}\right)$ were washed twice with PBS and resuspended in binding buffer $(500 \mu \mathrm{L})$. Cells were stained with FITC V $(5 \mu \mathrm{L})$ and $5 \mu \mathrm{L}$ PI, which were from the Annexin V-FITC Apoptosis Detection Kit, then incubated at RT $\left(25^{\circ} \mathrm{C}\right)$ for $15 \mathrm{~min}$ in the dark. Finally, all cells were analyzed by Flow Cytometry (Accuri-C6 BD, USA) within $1 \mathrm{~h}$. The experiments were repeated three times.

\section{Cell transfection}

Cells were transfected with Lipofectamine 2000 according to the instructions of the manufacturer (Life Technology). The experiment was designed with three groups: Mock group (transfection with only reagents), NC group (transfection with negative siRNA), and interference group (transfection with HSP70 siRNA).

\section{Western blot}

Cells were lysated using RIPA Buffer $(50 \mathrm{mM}$ Tris/HCL $\mathrm{pH}$ 8.0, $150 \mathrm{mM} \mathrm{NaCl}, 1 \%$ Nonidet-P40, 1\% Sodium deoxycholate, $0.1 \%$ SDS). Protein concentrations of the 


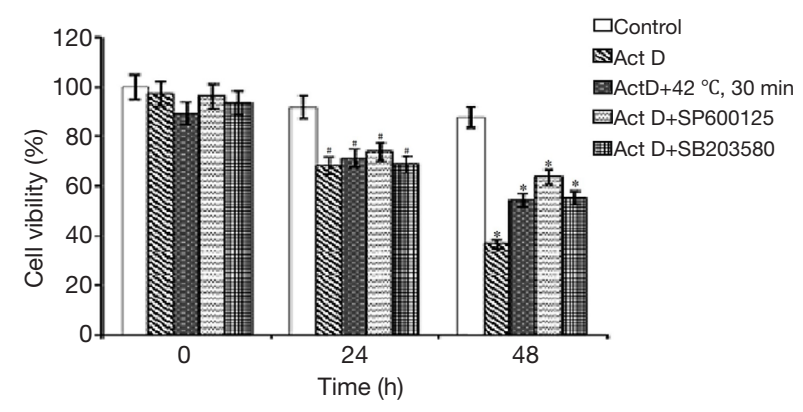

Figure 1 Mild heat treatment and JNK/p38 pathway inhibitors promoted cell proliferation in A549 cells. A549 cells were treated with ActD $(25 \mu \mathrm{g} / \mathrm{mL})$, mild heat treatment $\left(42{ }^{\circ} \mathrm{C}, 30 \mathrm{~min}\right)$ and pathway inhibitors SP600125 (20 $\mu \mathrm{M}, 40 \mathrm{nM}$ of IC50) and SB203580(20 $\mu \mathrm{M}, 500 \mathrm{nM}$ of IC50). Cell viability was detected using MTT assay at $0 \mathrm{~h}, 24 \mathrm{~h}$ and $48 \mathrm{~h}$ after treatments. The data are expressed as the mean \pm standard deviation of 3 independent experiments. *, the difference was significant $(\mathrm{P}<0.001)$ compared with control group; *, the difference was significant $(\mathrm{P}<0.05)$ compared with control group.

cell lysates were determined using the Bradford method. Absorbance was measured by Spectrophotometer (General Electric Company, USA). Protein samples were boiled in SDS sample buffer for $5 \mathrm{~min}$. Lysates with equal amount of proteins were analysed on $5 \%$ spacer gel and separating gel $(10 \%$ for HSP70 and p-JNK, or $12 \%$ for p-p38 and caspase-3). After SDS-PAGE, proteins in separating gel were transferred to PVDF membranes (Cowin Bioscience Co., Ltd. Beijing), and then were blocked with $5 \%$ skim milk for $2 \mathrm{~h}$ and washed using TBST ( $1 \mathrm{M}$ Tris- $\mathrm{HCl} \mathrm{pH}$ 7.5, $\mathrm{NaCl} 8.8 \mathrm{~g} / \mathrm{L}$, Tris $3 \mathrm{~g} / \mathrm{L}$, Tween $200.1 \%$ ) three times within $30 \mathrm{~min}$. The membranes were incubated with specific primary antibodies (anti- $\beta$-actin, anti-HSP70, antiPhos-JNK, anti-Phos-p38, and anti-caspase-3 antibodies) overnight at $4{ }^{\circ} \mathrm{C}$, and washed using TBST three times. Then the membranes were incubated for $2 \mathrm{~h}$ with HRPconjugated secondary antibody and washed three times. Finally, the blots on the membranes were detected by eECL kit (Cowin Bioscience Co., Ltd. Beijing) and developed with image film (Kodak, USA). The gray values of the bands on the images were analyzed by Quantity One.

\section{Statistical analysis}

The values are means \pm SD of three independent experiments. The difference between means was analyzed using oneway ANOVA. The statistical significance between the two means was determined using the Student-Newman-Keuls q test and the Dunnett q test (SPSS 21.0 software). P values less than 0.05 were considered significant.

\section{Results}

\section{Mild beat treatment and $7 N K / p 38$ pathway inbibitors promoted cell proliferation in $A 549$ cells}

We first determine the effect of mild heat treatment, SP600125, and SB203580 on cell proliferation by MTT assay. The results showed that treatment of the cells with mild heat and JNK/p38 pathway inhibitors (SP600125 and SB203580) was conducive to survival in the presence of ActD in A549 cells (Figure 1), which suggested that mild heat treatment or the JNK/p38 pathway might play an important role in apoptosis of A549 cells. The difference of cell viability among groups was significant $(\mathrm{P}<0.05)$. The result of the Dunnett q test $(2$-sided $)$ showed that cell viability decreased more quickly than with all other treatment groups at the 48 -h point $(\mathrm{P}<0.001)$.

\section{Mild beat treatment and $7 N K / p 38$ pathway inbibitors inhibited apoptosis in A549 cells}

To determine whether mild heat treatment or pathway inhibitors (SP600125 and SB203580) affected apoptosis of A549 cells, we investigated the effect of mild heat treatment on $\mathrm{A} 549$ cells treated with ActD using flow cytometry. The results showed that treatment with mild heat or SP600125 and SB203580 was able to significantly slow down the steps of apoptosis induced by ActD in A549 cells (Figure 2).

\section{Overexpression of HSP7O by mild heat inbibited the expression of the proteins involved in cell proliferation and apoptosis in A549 cells}

We next evaluated whether HSP70 overexpression induced by mild heat could inhibit the expression of the proteins involved in cell proliferation and apoptosis in actinomycinD-treated A549 cells by Western blot. As shown in Figure 3, HSP70 over-expression induced by mild heat markedly decreased the expression of p-JNK, p-p38 and caspase-3.

\section{Knockdown of HSP7O by HSPAIA-2009 induced the expression of the proteins involved in cell proliferation and apoptosis in $\mathrm{A} 549$ cells}

We also evaluate whether HSP70 down-regulation could 

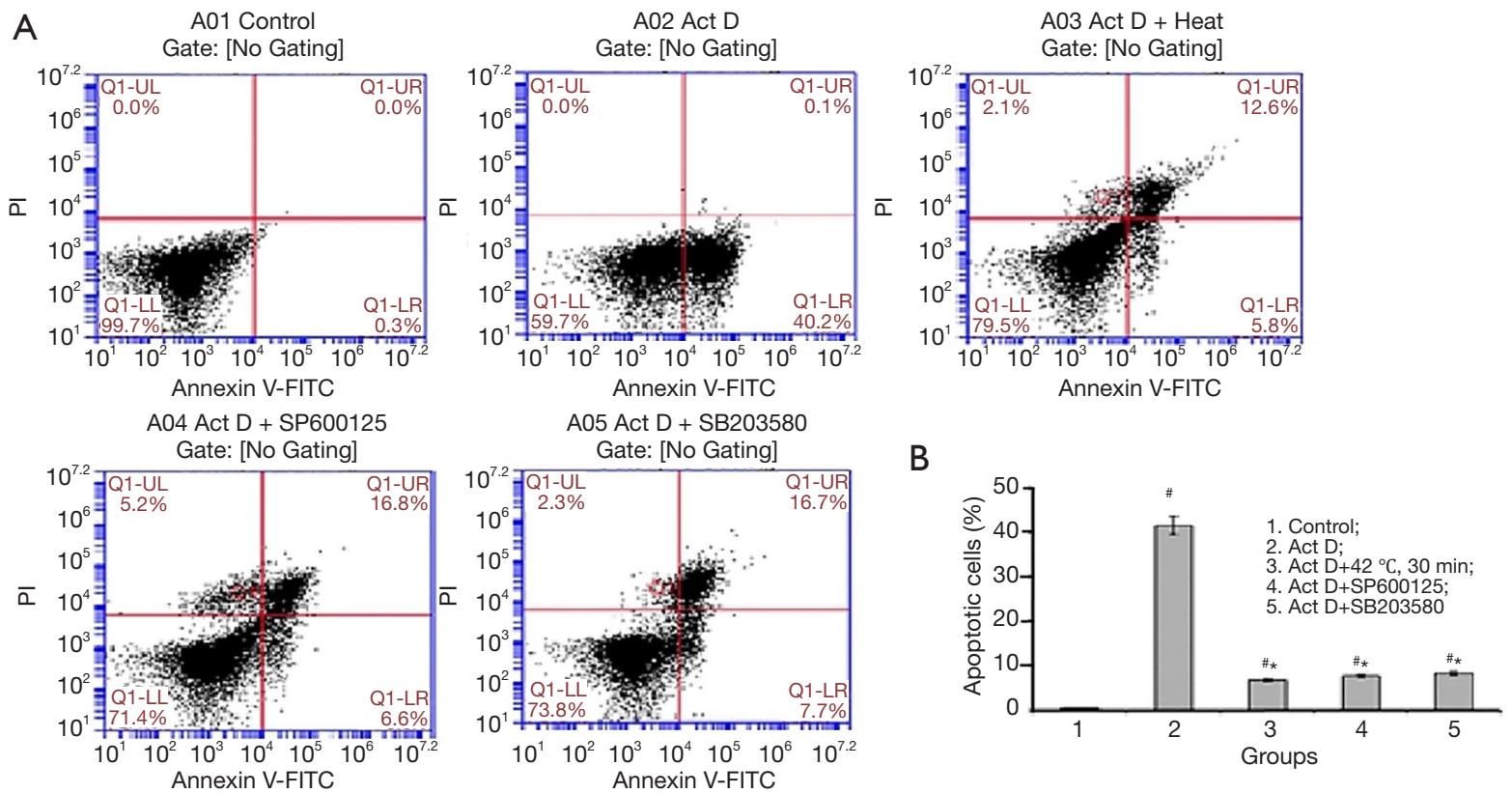

Figure 2 Mild heat treatment and JNK/p38 pathway inhibitors inhibited apoptosis in A549 cells. (A) Cell apoptosis was assessed by flow cytometry after staining with annexin V-FITC and PI. Designations A01-A05 indicate different treatment groups. A01. Control (DMSO). A02. ActD $(25 \mu \mathrm{g} / \mathrm{mL})$. A03. ActD and mild heat treatment $\left(42{ }^{\circ} \mathrm{C}, 30 \mathrm{~min}\right)$. A04. ActD and $20 \mu M$ SP600125 (JNK pathway inhibitor, IC50=40 nM). A05. ActD and $20 \mu \mathrm{M}$ SB203580 (p38 MAPK pathway inhibitor, IC50=500 nM). (B) Flow cytometry histogram of Q1-LR in (A). The data are expressed as the mean \pm standard deviation of 3 independent experiments. *, the difference was significant $(\mathrm{P}<0.05)$ compared with control group; *, the difference was significant $(\mathrm{P}<0.05)$ compared with ActD group.
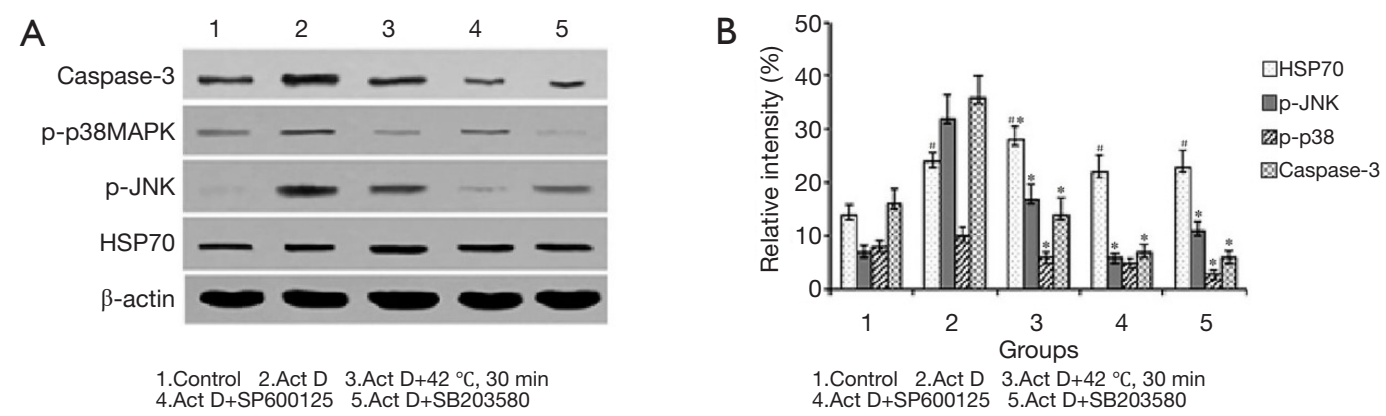

Figure 3 Overexpression of HSP70 by mild heat inhibited the expression of the proteins involved in cell proliferation and apoptosis in A549 cells. (A) Changes of protein expression were detected $24 \mathrm{~h}$ after treatments. Proteins were separated by SDS-PAGE and analyzed by immunoblotting with corresponding antibodies. Numbers indicate different treatment groups. 1: Control (DMSO). 2 : ActD (25 $\mu$ g/mL). 3: ActD and mild heat treatment $\left(42{ }^{\circ} \mathrm{C}, 30 \mathrm{~min}\right) .4$ : ActD and $20 \mu \mathrm{M}$ SP600125 (JNK pathway inhibitor, IC50=40 nM). $5:$ ActD and $20 \mu \mathrm{M}$ SB203580 (p38 MAPK pathway inhibitor, IC50=500 nM). (B) Relative protein expression was showed by histogram. The data are expressed as the mean \pm standard deviation of 3 independent experiments. *, the difference was significant $(\mathrm{P}<0.05)$ compared with control group; *, the difference was significant $(\mathrm{P}<0.05)$ compared with ActD group. 

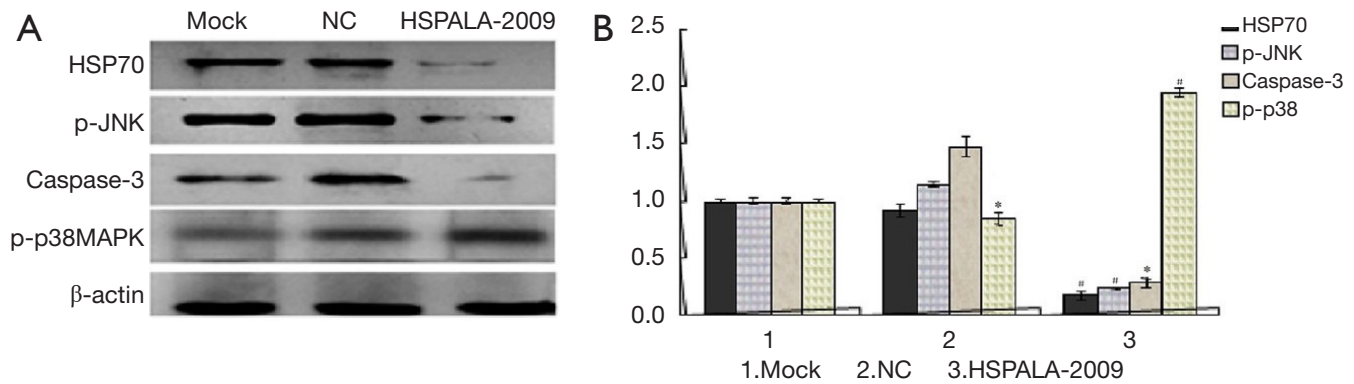

Figure 4 Knockdown of HSP70 by HSPAIA-2009 induced expression of the proteins involved in cell proliferation and apoptosis in A549 cells. (A) A549 cells were transfected with HSPAIA-2009 using lipofectamine. Mock group was only treated with lipofectamine 2000 but not siRNA. Transfected NC-siRNA was used as negative control. (B) The relative expressions of proteins were showed by histogram. The data are expressed as the mean \pm standard deviation of 3 independent experiments. Difference of suppression of proteins in groups was significant $(\mathrm{P}<0.05)$. *, the difference was significant $(\mathrm{P}<0.05)$ compared with mock group; ${ }^{\#}$, the difference was significant $(\mathrm{P}<0.05)$ compared with mock and NC group.

increase the expression of the proteins associated with cell proliferation and apoptosis in A549 cells by Western blot. The results showed that knockdown of HSP70 by siRNA HSPAIA-2009 effectively promoted the expression of p-p38 MAPK and decreased the expression of $\mathrm{p}-\mathrm{JNK}$ MAPK (Figure 4).

\section{Discussion}

Lung cancer is the leading cause of cancer-associated death around the world. A549 cells have been used for the research of lung cancer development and the analysis on the correlation of diagnosis and treatment of tumor $(1,2)$. Based on the cell characteristics, we used human lung epithelial cells as the research object in our study (12), and chose ActD as apoptosis inducer (13). We also found that $25 \mu \mathrm{g} / \mathrm{mL}$ is a poisonous dose of MTT. SB203580 is one of the most common inhibitors of the p38 MAPK pathway, which can competitively combine the p38 lightning ATP binding site and inhibit the phosphorylation level. SP600125 is a selective inhibitor of ATP competitive JNK, which is a broad inhibitor of JNK inhibitors. JNK is a key member in the family of MAPK signal pathway. HSP70 can inhibit upstream kinases JNK and ASK1 or directly inhibit JNK to the inhibition of MAPK-mediated apoptosis.

We found that cell apoptosis increased with ActD processing, accompanied by increased p-p38 and p-JNK expression, and the result was opposite when inhibitors were added, which suggests that the actinomycin-D-induced apoptosis of A549 cells was mediated by MAPK. We also used siRNA to reduce the expression level of HSP70 in
A549 cells, and detected the expression levels of HSP70, p-JNK, and activated caspase-3 by Western blot. We found that the down-regulation of HSP70 was able to induce lower expression levels of $\mathrm{p}-\mathrm{JNK}$ and activated caspase-3. However, transfecting NC-siRNA was able to increase the expression level of activated caspase-3. Moreover, we further detected the apoptosis rate by flow cytometry, showing that HSPA1A-2009 transfection down-regulated HSP70 and increased p38 MAPK significantly. HSP70 expression was increased after heat treatment, but the cell apoptosis was declined and p-JNK and p-p38 expression was decreased. Knockdown of HSP70 was able to inhibit the proliferation of A549 cells, and promote cell apoptosis. This process was accompanied by the decreased activation of JNK and the increased activation of p38 MAPK. Research has shown that in nearly all living cells, heat shock protein can be induced (14). It has been shown that HSP70 is expressed on surfaces of a variety of tumors and participates in the immune protection of tumors. Increased levels of extracellular HSP70 may participate in establishing the immunosuppressive tumor milieu, and thus further support the establishment of tumors and metastases (15). Increased levels of extracellular HSP70 may participate in establishing the immunosuppressive tumor milieu, and thus further support the establishment of tumors and metastases $(5,15)$. It plays an important role in cancer development, HSP70 has been shown to be essential for invasion and metastasis in the PyMT-driven mouse spontaneous MMT mammary tumor and in human mammary lines (16), and can also induce apoptosis signal-regulating lines I and apoptosis inducing factor (AIF) interaction to prevent 
caspase independent cell death (17).

Caspase- 3 is an important member of the caspase family, and it is the ultimate enforcer of caspase dependence on apoptosis process (18). There are two different pathways of apoptosis, one pathway is inside the cell, and the other is the extracellular pathway. After cells accept the apoptotic signal, FasL and TNF combine with the related receptors, which activate caspase 8 or 10 . The formed complexes cause downstream activation of apoptosis executives caspase-3, -6 , and -7 . The intrinsic pathway inside the cell is also called the mitochondrial pathway. The apoptotic signal promotes mitochondria to release cytochrome $\mathrm{c}$ and activate caspase-9 and caspase-3 $(18,19)$. Our study demonstrated the activation level of caspase- 3 signaling by detecting the activation of caspase- 3 p17 subunits. Our results show that that cell apoptosis declined after higher HSP70, with caspase- 3 activation level reduced. Cell apoptosis increased after siRNA knockdown of HSP70 and caspase-3 activation was reduced. The results suggest that siRNA knockdown HSP70 can promote cell apoptosis without caspase-3. Previous studies have found that apoptosis depending on caspase- 3 is not the only way the process of apoptosis transpires in myocardial cells (20). The cell-apoptosis process can be directly released by apoptosis-inducing factor(AIF), induced by mitochondria (21), or mediated by endoplasmic stress bypass caspase: there are 3 ways to start the apoptotic cascade $(22,23)$.

\section{Conclusions}

In summary, our results showed that HSP70 expression inhibited p38 MAPK pathway activation, which in turn inhibited p38 MAPK pathway-mediated apoptosis process. Knockdown of HSP70 in A549 cells inhibited cell proliferation and promoted cell apoptosis, along with the activation of JNK and caspase-3. The possible mechanism is that external stimuli such as ActD induce cell apoptosis through the MAPK pathway. Caspase-3 performs apoptosis, and elevated HSP70 inhibit apoptosis of this way. However, while cells are not stimulated and HSP70 is inhibited, the occurrence of apoptosis can rely on the pathway without caspase- 3 . The inhibition of apoptosis is one of the main features of tumor cells. Therefore, exploring the mechanism associated with apoptosis has important implications for cancer prevention.

\section{Acknowledgments}

Funding: This work was supported by the National Natural
Science Foundation of China (Grant No. 81803206) and the Ministry of Education of Science and Technology research foundation of Henan province (Grant No. 172102310267).

\section{Footnote}

Conflicts of Interest: All authors have completed the ICMJE uniform disclosure form (available at http://dx.doi. org/10.21037/tcr.2019.12.100). The authors have no conflicts of interest to declare.

Ethical Statement: The authors are accountable for all aspects of the work in ensuring that questions related to the accuracy or integrity of any part of the work are appropriately investigated and resolved.

Open Access Statement: This is an Open Access article distributed in accordance with the Creative Commons Attribution-NonCommercial-NoDerivs 4.0 International License (CC BY-NC-ND 4.0), which permits the noncommercial replication and distribution of the article with the strict proviso that no changes or edits are made and the original work is properly cited (including links to both the formal publication through the relevant DOI and the license). See: https://creativecommons.org/licenses/by-nc-nd/4.0/.

\section{References}

1. Sacco PC, Casaluce F, Sgambato A, et al. Current challenges of lung cancer care in an aging population. Expert Review of Anticancer Therapy 2015;15:1419-29.

2. Goss PE, Lee BL, Badovinac-Crnjevic T, et al. Planning cancer control in Latin America and the Caribbean. The Lancet Oncology 2013;14:391-436.

3. Tan W L, Jain A, Takano A, et al. Novel therapeutic targets on the horizon for lung cancer. The Lancet Oncology 2016;17:e347-62.

4. Lang BJ, Guerrero-Gimenez ME, Prince TL, et al. Heat Shock Proteins Are Essential Components in Transformation and Tumor Progression: Cancer Cell Intrinsic Pathways and Beyond. Int J Mol Sci 2019. doi: 10.3390/ijms20184507.

5. Shevtsov M, Huile G, Multhoff G. Membrane heat shock protein 70: a theranostic target for cancer therapy. Philos Trans R Soc Lond B Biol Sci 2018. doi: 10.1098/ rstb.2016.0526.

6. Mori Y, Terauchi R, Shirai T, et al. Suppression of heat shock protein 70 by siRNA enhances the antitumor effects 
of cisplatin in cultured human osteosarcoma cells. Cell Stress Chaperones 2017;22:699-706.

7. Liu J, Liu J, Guo SY, et al. HSP70 inhibitor combined with cisplatin suppresses the cervical cancer proliferation in vitro and transplanted tumor growth: An experimental study. Asian Pac J Trop Med 2017;10:184-8.

8. Yang X, Wang J, Zhou Y, et al. Hsp70 promotes chemoresistance by blocking Bax mitochondrial translocation in ovarian cancer cells. Cancer Lett 2012;321:137-43.

9. Endo H, Yano M, Okumura Y, et al. Ibuprofen enhances the anticancer activity of cisplatin in lung cancer cells by inhibiting the heat shock protein 70. Cell Death Dis 2014;5:e1027.

10. Bienemann AS, Lee YB, Howarth J, et al. Hsp70 suppresses apoptosis in sympathetic neurones by preventing the activation of c-Jun. J Neurochem 2008;104:271-8.

11. Gong X, Luo T, Deng P, et al. Stress-induced interaction between p38 MAPK and HSP70. Biochem Biophys Res Commun 2012;425:357-62.

12. Budina-Kolomets A, Balaburski GM, Bondar A, et al. Comparison of the activity of three different HSP70 inhibitors on apoptosis, cell cycle arrest, autophagy inhibition, and HSP90 inhibition. Cancer Biol Ther 2014;15:194-9.

13. Zajkowicz A, Krzesniak M, Gdowicz-Klosok A, et al. PIM2 survival kinase is upregulated in a p53-dependent manner in cells treated with camptothecin or co-treated with actinomycin D and nutlin-3a. Arch Biochem Biophys 2018;655:26-36.

14. Shi YY, Small GW, Orlowski RZ. Proteasome inhibitors

Cite this article as: Zhang $\mathrm{K}$, Zhai R, Xue T, Xu X, Ren Y, Ma M, Shi F, Wang H, Wang N, Zhou F. HSP70 regulates cell proliferation and apoptosis in actinomycin-D-treated lung cancer cells. Transl Cancer Res 2020;9(2):1167-1173. doi: 10.21037/tcr.2019.12.100 induce a p38 mitogen-activated protein kinase (MAPK)dependent anti-apoptotic program involving MAPK phosphatase-1 and Akt in models of breast cancer. Breast Cancer Res Treat 2006;100:33-47.

15. Shevtsov M, Multhoff G. Heat Shock Protein-Peptide and HSP-Based Immunotherapies for the Treatment of Cancer. Front Immunol 2016;7:171.

16. Gong J, Weng D, Eguchi T, et al. Targeting the hsp70 gene delays mammary tumor initiation and inhibits tumor cell metastasis. Oncogene 2015;34:5460-71.

17. Ravagnan L, Gurbuxani S, Susin SA, et al. Heat-shock protein 70 antagonizes apoptosis-inducing factor. Nat Cell Biol 2001;3:839-43.

18. Green DR, Llambi F. Cell Death Signaling. Cold Spring Harb Perspect Biol 2015. doi: 10.1101/cshperspect. a006080.

19. Shi Y. Mechanisms of caspase activation and inhibition during apoptosis. Mol Cell 2002;9:459-70.

20. Xia LM, Tian DA, Zhang Q, et al. Inhibition of HSP702 expression by RNA interference induces apoptosis of human hepatocellular carcinoma cells. Zhonghua Gan Zang Bing Za Zhi 2008;16:678-82.

21. Sevrioukova IF. Apoptosis-inducing factor: structure, function, and redox regulation. Antioxid Redox Signal 2011;14:2545-79.

22. Asea A. Stress proteins and initiation of immune response: chaperokine activity of hsp72. Exerc Immunol Rev 2005;11:34-45.

23. Asea A. Heat shock proteins and toll-like receptors. Handb Exp Pharmacol 2008:111-27. 